\title{
Power Flow in A Load-Current Sensorless Shunt Active Power Filter
}

\author{
Hanny H. Tumbelaka \\ Electrical Engineering Department, Petra Christian University \\ Jl. Siwalankerto 121-131 Surabaya 60236 Indonesia \\ E-mail: tumbeh@petra.ac.id
}

\begin{abstract}
In this paper, power flow analysis of a three-phase four-wire system with a shunt active power filter in steady stateis presented. The analysis begins with a mathematical model of the power inverter and continues to find therelationship ofthe real and imaginary power as well as zero sequence power in the grid, loads, and the inverter (AC and DC sides) for successful compensation. The system includes mixed non-linear loads with significant unbalanced components. The flter consists of a three-phase current-controlled voltage source inverter (CC-VSI) with a filterinductance at the AC output and a DC-bus capacitor. The CC-VSI is operated to directly control the AC grid cument to besinusoidal and in phase with thegrid voltage. Computer simulation results verify the concept of the filter and the power flow.
\end{abstract}

Keywords: active power filter, power flow

\begin{abstract}
ABSTRAK
Dalam makala ini disajikan analisa aliran daya dari sistem tiga-fasa empat-kawat dengan sebuah shunt adivepower filter dalam keadaan ajek. Analisa dimulai dengan model matematika dari power inverter dan dilanjutkan dengan mencari hubungan antara daya nyata, imajiner, dan urutan nol pada sumber, beban, dan inverter(sisi AC dan DC) untukproses kompensasi yang berhasil. Dalam sistem ini terdapat bermacam beban tidak linier yangjuga tidakseimbang. Sedangkan filternya terdiri dari current-controlled voltage source inverter (CC-VSI) tiga fasa yang dilengkapi dengan indultansi filter pada keluaran AC dan kapasitor DC-bus. CC-VSI beroperasi untuk mengendalikan arus sumber AC secara langsung agar menjadi sinus dan sefasa dengan tegangan sumber. Hasil simulasi komputer bersesuaiandengan konsep dari filter dan aliran daya.
\end{abstract}

Kata kunci:active power filter, aliran daya

\section{INTRODUCTIO N}

Non-linear loads, especially power electronic loads, create harmonic currents and voltages in thepower systems. For many years, various adtive power filters (APF) have been developed to suppress the harmonics, as well as compensate for reactive power, so that the utility grid will supply sinusoidal voltage and current with unity power factor [1][2].

In this paper, the three-phase shunt APF is a combination of a grid current-controllingshunt APF integrated with a seriesreactor installedat the Point of Common Coupling (PCC) to handle theharmonic and unbalance problems from mixed loads (see Figure 1) [3]. This novel shunt APF has been developed to overcome the problems occurredin the conventional shunt APF.

Note: Discussion is expected before June, $1^{\text {st }}$ 2007. The proper discussion will be published in Electrical Engineering Journal volume 7, number 2, September 2007.
Conventionally, the power inverter as a shunt APF is controlled in such a way as to inject equal-butopposite harmonic and reactive compensation currents based on calculated reference currents. Hence, the current sensors are installedon the load side. Then, their output signals will beprocessedto construct the reference or desired currents, which consist of harmonic and reactive components as well as negative- and zero-sequence components for unbalance compensation. Once the desiredreference currents have been established, the currentsmust be injected into the grid accurately using a current control mechanism. The actual inverter currentsmust attempt to follow the reference currents with high bandwidth. In addition, the DC-busvoltage hasto be kept constant to compensate for the inverter losses.

In contrast, the novel APF is operated to directly control the AC grid current to be sinusoidal andin phase with the grid voltage. By doing this, the threephase shunt APF automatically provides compensation for harmonics, reactive (imaginary) power and unbalance. 


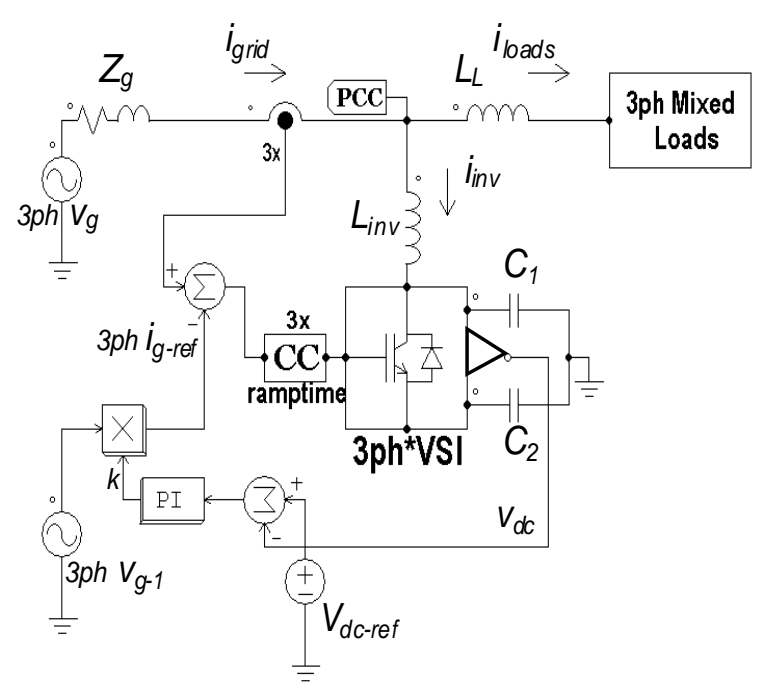

Figure 1. Block diagram of the shunt APF

There are many advant ages of directly controllingthe grid current. Firstly, it is easy to create a simple sinusoidal reference for the grid current. The reference current is an appropriate reference to minimize the grid harmonic currents. Secondly, the grid currents produced will be sinusoidal, balanced and in phase with the grid voltage regardless of gid voltage conditions. Thus, it prevents (more) pollution of the electrical system from non-linear loads. Furthermore, there are three current sensorsinstalled at the grid side instead of six current sensors in a conventional shunt APF. The controlmechanism becomes very simple as well.

Moreover, a shunt APF cannot properly compensate for harmonic voltage sources. In many cases, nonlinear loads consist of combinations of harmonic voltage sources and harmonic current sources, and may contain significant load unbalance (ex. single phase loads on a three phase system). The addition of a small series inductance, $X_{L}$ is simple, effective and practical not only to provide the requiredvoltage decoupling between voltage type of loadharmonic sources and the PCC but also to reduce the bandwidth of the load harmonic currents [4].

Due to its functions, the existence of the shunt APF may change the distribution of power between the grid and the load. Hence, power is flowing in the grid, the load and the inverter. It is expressedin terms of real power and imaginary power, which consist of an average value and an oscillatingvalue. The relationship of these terms to the conventional concept about active, reactive and harmonic power can be seen in [5]. In this paper, power flowin thepower system as well as in the shunt APF will be investigated.

\section{SHUNT AC TIVE PO WER FILTER O PERATIO N}

The three-phase shunt active power filter is athreephase current-controlledvoltage-source inverter (CCVSI) with a mid-point earthedsplit capacitor $\left(C_{1}\right.$ and $C_{2}$ ) in the DC bus and inductors $\left(L_{i n v}\right)$ in the AC output. Thus, it is essentially three independent singlephase inverters with a common DC bus.

The APF consists of two control loops, namely an inner control loop andan outer control loop. The inner control loop is a ramptimecurrent control [6][7] that shapes the grid currents to be sinusoidal by generating a certain pattern of PWM for continuousswitching of the inverter switches, whilethe outer control loop is a simple Proportional Integral (PI) control to keep the DC bus voltage constant and to provide the magnitude of reference current signals.

\section{Direct Control of the Grid Current}

In this scheme (see Figure 1), the CC-VSI is operated to directly control the AC gidcurrent rather than it's own current. The grid current is sensedby putting the current sensors on the grid side andforcedto behave as a sinusoidal current source. The gridappears asa high-impedance circuit for harmonics. By forcingthe grid current to be sinusoidal, the APF automatically provides the harmonic, reactive, negative andzero sequence currents for the load, followingthe basic current summation rule:

$i_{\text {grid }}=i_{\text {inverter }}+i_{\text {loads }}$

The sinusoidal grid current reference signal is given by:

$i_{g r e f}=k v_{\text {grid }-1}$

where $v_{\text {grid-1 }}$ is the fundamental component of the grid voltage, and $k$ is obtained from an outer control loop regulating the CC-VSI DC-bus voltage. Thiscan be accomplished by a simple PI control loop. This is an effective way of determining the requiredmagnitude of active current required, since any mismatch between the required load active current andthat being forced by the CC-VSI would result in the necessary corrections to regulate theDC-busvoltage.

\section{Series Inductance [4]}

Another key component of this system isthe added series inductance $X_{L}$, which is comparable in value to the effective gridimpedance, $Z_{g}$. Without this inductance, load harmonic voltage sources would produce harmonic currents through the gridimpedance, which could not be compensatedby a shunt 
APF. Currents from the APF do not significantly change the harmonic volt age at the loads. Therefore, there are still harmonic voltages across the grid impedance, which continue to produce harmonic currents. The inductance $X_{L}$ provides the required voltage decoupling between load harmonic voltage sources and the grid.

\section{POWER INVERTER MO DEL}

The three-phase power distribution system with the shunt active power filter along with integrated series inductors is described in Figure 2. The devicesare assumed to be the same for the three phases. Applying Kirchoff's rulesto thissystem, the voltages of the grid, the load and the output inverter are given by:

$$
\begin{aligned}
& v_{g-j}-v_{p c c-j}=R_{g} i_{g-j}+L_{g} \frac{d i_{g-j}}{d t} \\
& v_{p c c-j}-v_{L-j}=R_{L} i_{L-j}+L_{L} \frac{d i_{L-j}}{d t} \\
& v_{p c c-j}-v_{i n v-j}=R_{i n v} i_{i n v-j}+L_{i n v} \frac{d i_{i n v-j}}{d t}
\end{aligned}
$$

For a three-phase system, the sum of the instantaneous three-phase voltages and currentsiszero. The current relationship at the point of common coupling (PCC) is given by:

$$
i_{g-j}=i_{i n v-j}+i_{L-j}
$$

where $j=\{a, b, c\}$

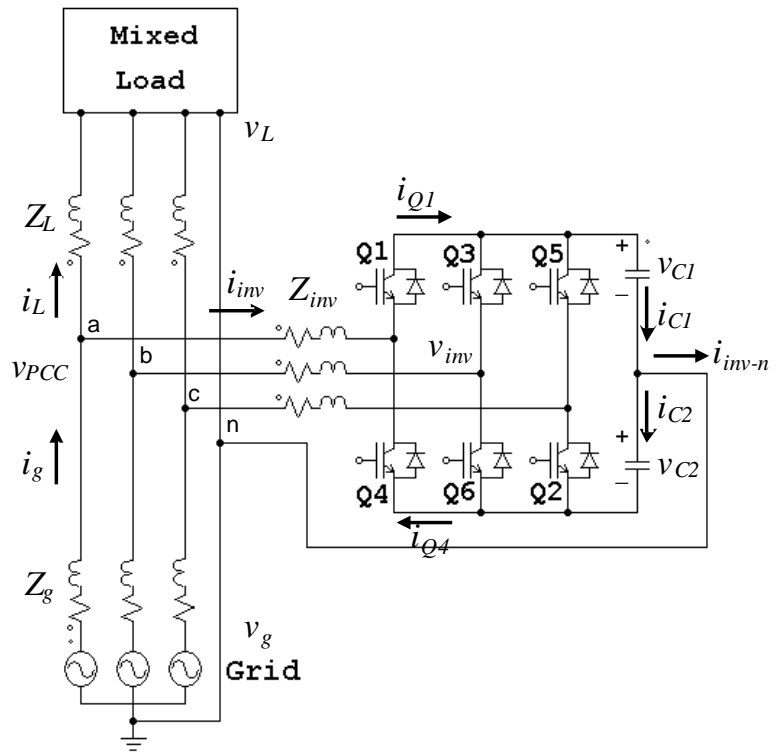

Figure 2. Power Circuit

By controlling the switches, the PWM CC-VSI output voltages $v_{i n v-j}$ can be expressed in terms of DC- bus voltages (assuming the voltages are constant over the switching period) and the continuous duty ratios of the switches, which is denoted by $d_{j}$ :

$$
\begin{aligned}
& v_{i n v-j}=d_{j} v_{C 1}+\left(d_{j}-1\right) v_{C 2} \\
& v_{d c}=v_{C 1}+v_{C 2}
\end{aligned}
$$

The value of $d_{j}$ varies from zero to one. Another expression for $d_{j}$ in terms of the voltages can be found directly from equations (7) and (8):

$$
d_{j}=\frac{v_{i n v-j}+v_{C 2}}{v_{d c}}
$$

Therefore, as seen from the AC side, the power inverter (converter) can be modelledin time average as a voltage-controlled voltage source(VCVS) with the parameter of $v_{i n v}$.

On the DC side, the modelling begins with the expression of the current through each bidirectional switch $Q_{j}$. For phase A, the average current $i_{Q 1}$ is equal to $d_{a} i_{\text {inv-a }}$, while $i_{Q 4}$ is equal to $\left(d_{a}-1\right) i_{\text {inva }}$. Thus, in general, the average bidirectional switch currents can be written as functions of inverter output currents, namely:

$$
\begin{aligned}
& i_{Q(\text { top })-j}=d_{j} i_{i n v-j} \\
& i_{Q(\text { bottom })-j}=\left(d_{j}-1\right) i_{i n v-j}
\end{aligned}
$$

On the DC side, the current flowingto capacitor $C_{1}$ is $i_{C 1}$, and to capacit or $C_{2}$ is $i_{C 2}$. The currents $i_{C 1}$ and $i_{C 2}$ each are equal to the total currents through their respective bidirectional switches, and are simply expressed as follows:

$$
\begin{aligned}
& i_{C 1}=\sum_{j=a, b, c} d_{j} i_{i n v-j} \\
& i_{C 2}=\sum_{j=a, b, c}\left(d_{j}-1\right) i_{i n v-j}
\end{aligned}
$$

Thus, on the DC side, the converter ismodelledin time average by a current-controlledcurrent-source (CCCS) with DC-capacitor currents.

Equations (12) and (13) regarding DC-capacitor currents can be rearrangedusing Equations(5) and(9) to observe the influence of the parameters from the AC side of the inverter. After some algebraic manipulation, the currentsin DC capacitors $C_{1}$ and $C_{2}$ are given by:

$$
\begin{aligned}
i_{C 1}= & \sum_{j=a, b, c} \frac{1}{v_{d c}}\left(v_{C 2} i_{i n v-j}+v_{p c c-j} i_{i n v-j}-\right. \\
& \left.L_{i n v} \frac{d i_{i n v-j}}{d t} i_{i n v-j}-R_{i n v} i_{i n v-j}^{2}\right)
\end{aligned}
$$




$$
\begin{aligned}
i_{C 2}= & \sum_{j=a, b, c} \frac{1}{v_{d c}}\left(-v_{C 1} i_{i n v-j}+v_{p c c-j} i_{i n v-j}-\right. \\
& \left.L_{i n v} \frac{d i_{i n v-j}}{d t} i_{i n v-j}-R_{i n v} i_{i n v-j}^{2}\right)
\end{aligned}
$$

Based on equation (7) and equations (12) and(13), the inverter equivalent circuitscan beillustratedas in Figure 3.

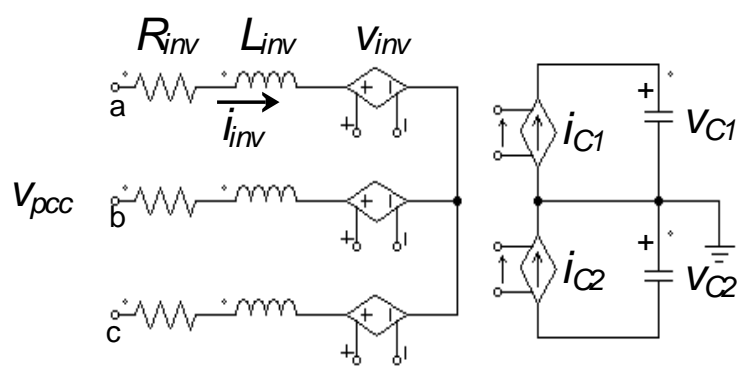

Figure 3. Equivalent Circuit of the Inverter

\section{POWER FLOW}

Power flow analysis of this system in steady state is similar to that undertaken by Akagi [8][9]. Considering a non-sinusoidal andunbalancedsystem, the load power consists of real power $p_{L}$, imaginary power $q_{L}$ and zero sequence power $p_{L-0}$, which consist of an average value andan oscillating value as mentioned above:

$$
\begin{aligned}
& p_{L}=\bar{p}_{L}+\tilde{p}_{L} \\
& q_{L}=\bar{q}_{L}+\tilde{q}_{L} \\
& p_{L-0}=\bar{p}_{L-0}+\tilde{p}_{L-0}
\end{aligned}
$$

The shunt active power filter has to compensate for the unwanted currents of the load so that after successful compensation, the grid currents will be sinusoidal and in-phase with the grid voltage. Asa result, if the grid voltage is non-sinusoidal andor unbalanced, the powers $p_{g}, q_{g}$ and $p_{g-0}$ generated from the grid become:

$$
\begin{aligned}
& p_{g}=\bar{p}_{g}+\tilde{p}_{g} \\
& q_{g}=\tilde{q}_{g} \\
& p_{g-0}=0
\end{aligned}
$$

To achieve sinusoidal grid currents, both powers $\tilde{p}_{g}$ and $\tilde{q}_{g}$ still exist in the grid in small values. The power developed by the inverter is calculated by subtracting the power supplied by the gridandthe power consumed by the load, given by:

$$
\left[\begin{array}{c}
p_{i n v} \\
q_{i n v} \\
p_{i n v-0}
\end{array}\right]=\left[\begin{array}{c}
p_{g} \\
q_{g} \\
p_{g-0}
\end{array}\right]-\left[\begin{array}{c}
p_{L} \\
q_{L} \\
p_{L-0}
\end{array}\right]
$$

From Equations (16) and (17), Equation (18) can be expressed in terms of average and oscillatingvalues as:

$$
\left[\begin{array}{c}
p_{i n v} \\
q_{i n v} \\
p_{i n v-0}
\end{array}\right]=\left[\begin{array}{c}
\bar{p}_{g}-\bar{p}_{L} \\
-\bar{q}_{L} \\
-\bar{p}_{L-0}
\end{array}\right]+\left[\begin{array}{c}
\tilde{p}_{g}-\tilde{p}_{L} \\
\tilde{q}_{g}-\tilde{q}_{L} \\
-\tilde{p}_{L-0}
\end{array}\right]
$$

From Equation (19), the characteristics of the power flow in the system can be described as follows:

1. The inverter supplies the zero sequence average (active) $\bar{p}_{L-0}$ and oscillating $\tilde{p}_{L-0}$ power needed by the load.

2. To supply the load zero sequence adtive power, the inverter has to take an active power from the grid because the inverter has no DCsource(only DC capacitors in the DC bus). Neglecting the losses in the power converter, in steady state, the active power consumed by the loadisequal to the active power supplied by the grid, andtotal active power flowing to the inverter iszero. Theactive (average) power in Equation (19) can be combined as:

$$
\bar{p}_{i n v}+\bar{p}_{i n v-0}=\bar{p}_{g}-\bar{p}_{L}-\bar{p}_{L-0}=0 \text {. }
$$

Because $\bar{p}_{i n v-0}=-\bar{p}_{L-0}$, thus, the active power taken from the grid by the inverter, which is used to support the zero sequence power deliveredto the load, is $\bar{p}_{i n v}=\bar{p}_{g}-\bar{p}_{L}=\bar{p}_{L-0}$. Additional power consumption is required to compensate for the losses, so that $\bar{p}_{i n v}=\bar{p}_{L-0}+\bar{p}_{\text {loss }}$.

3. The active power filter supplies $\tilde{p}_{L}$ as wellas $\tilde{p}_{L-0}$ and consumes $\tilde{p}_{g}$ using DC capacitorsas an energy storage element. Hence, thispower will appear in the DC-bus voltage ripple. Normally, $\widetilde{p}_{g}$ is small so that the DC-bus voltage predominantly reflects the load power.

4. The inverter controls the whole imaginary power associated with the load $\bar{q}_{L}+\tilde{q}_{L}$ andthe grid $\tilde{q}_{g}$.

\section{SIMULATIO N RESULTS}

The system in Figure 1 is tested using computer simulation (PSIM) to verify the concept above. In this case, the grid voltage is made unbalanced. The fundamental component of the phase-A voltage is increased by $10 \%$. The three-phase grid voltage is shown in Figure 4. The three-phase current waveforms of the mixed loads, as well asthe neutral current from the computer simulation, are shown in Figure 5. Figure 6 demonstrates the steady-state performance of compensation results. It can be seen that the shunt APF is successfully able to compensate for the total mixed loads that produce harmonic, 
reactive and unbalanced currents. It isobvious that the CC-VSI is able to generate three different currentsfor each phase as well as the neutral current, as shown in Figure 7. Hence, the inverter also providesbalancing to create the symmetrical grid currents.

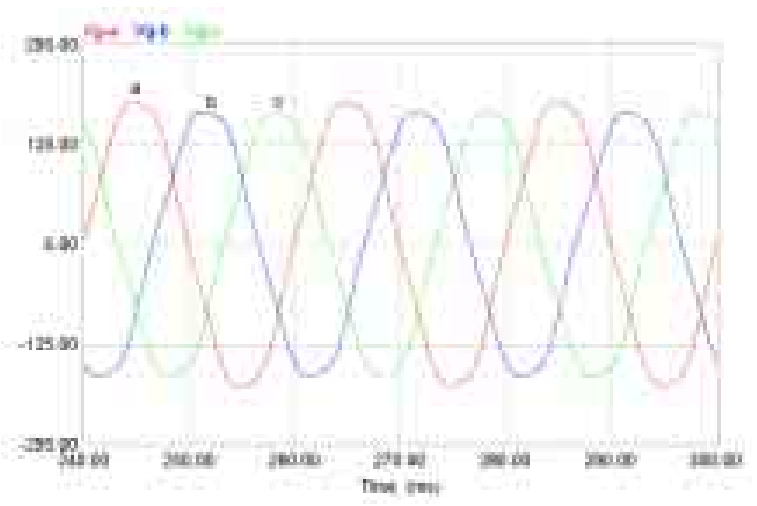

Figure 4. Grid voltages - unbalance and harmonics

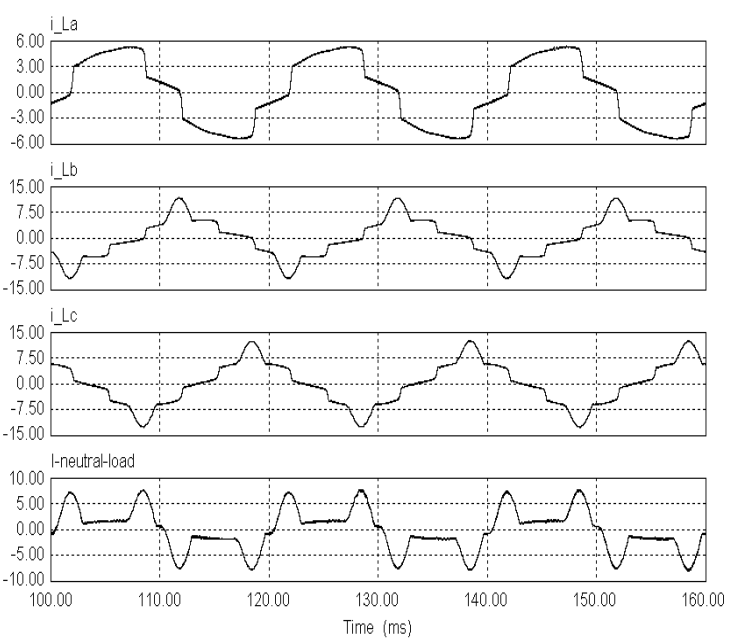

Figure 5. Load currents

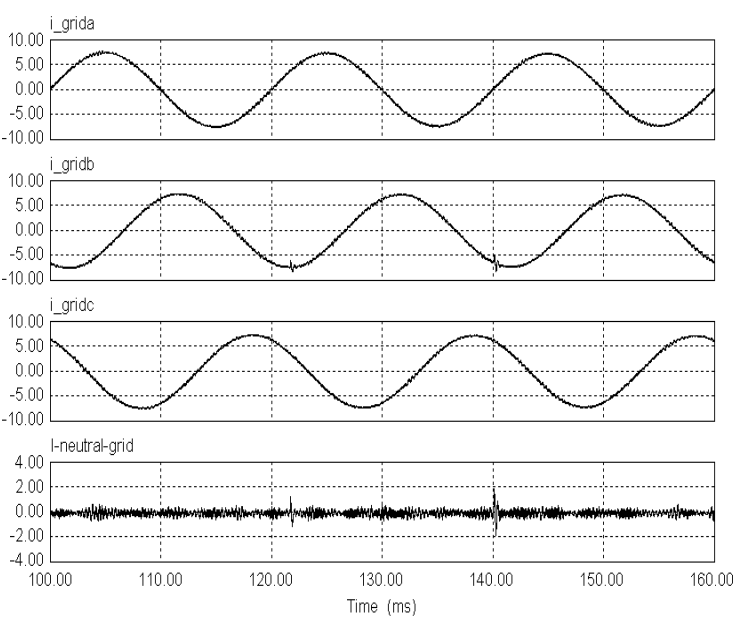

Figure 6. Grid currents after compensation

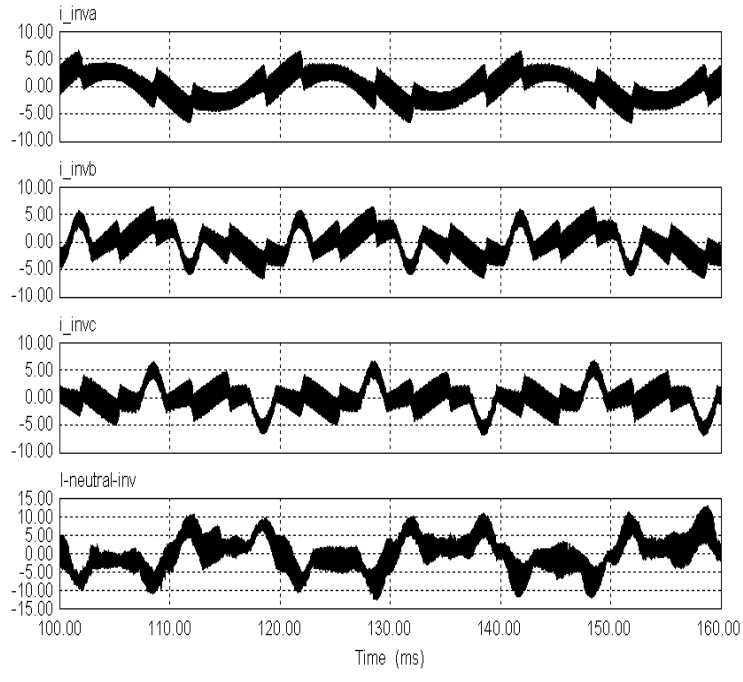

Figure 7. Inverter currents

Figure 8 shows the relationship of the real power from the grid, the load and the inverter. It is clear that $p_{i \text { iv }}=$ $p_{g}-p_{L}$. Both waveforms are the same andcontain a small average value, which corresponds to zero sequence power as well as lossesabsorbedby the OCVSI. Figure 9 shows that the zero sequence power of the load is compensated for by the CG-VSI, while the zero sequence power of the gidisclose to zero. Thus, the grid supplies the required zero sequence active power to the inverter, and then the inverter delivers the power to the load. From Figure 10, the relationship of the imaginary power from the gid, the load and the inverter is demonstrated Finally, the gid supplies the real power as shown in Figure 11, which agrees with Equation (17). The gidgeneratesa small reactive power $\bar{q}_{g}$ because the gridcurrentsleadthe voltages by approximately $1^{0}$ due to the highfrequency switching filter. Shiftingthe gidreference current by a small negative value can eliminate the reactive power. Hence, computer simulation results verify the power flow in Equation (19).

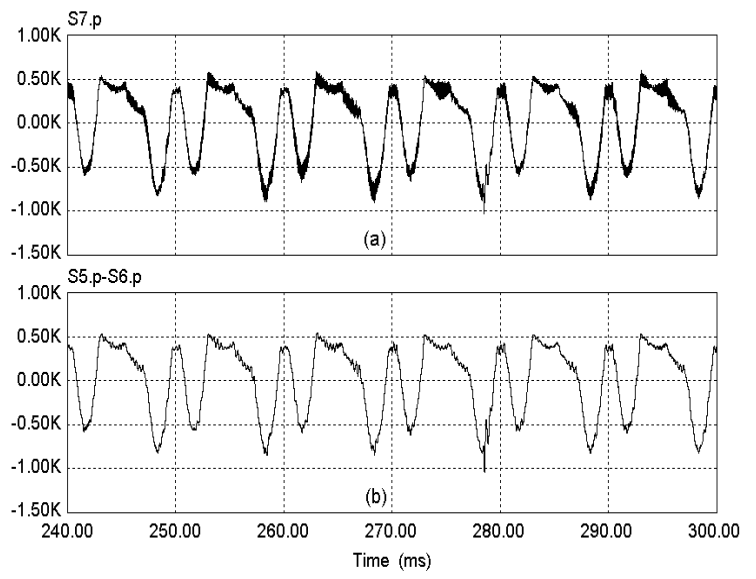

Figure 8. Real power (a) $\mathrm{p}_{\text {inv }}$ (b) $\mathrm{p}_{\mathrm{g}}-\mathrm{p}_{\mathrm{L}}$ 


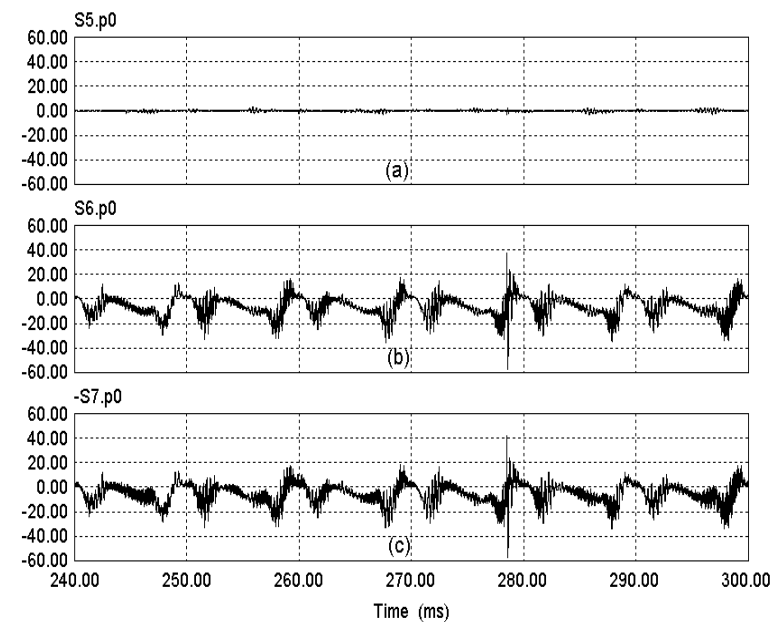

Figure 9. Zero sequence power (a) $\mathrm{p}_{\mathrm{g} 00}$ (b) $\mathrm{p}_{\mathrm{L} 0}$ (c) $\mathrm{p}_{\mathrm{inv} 0}$

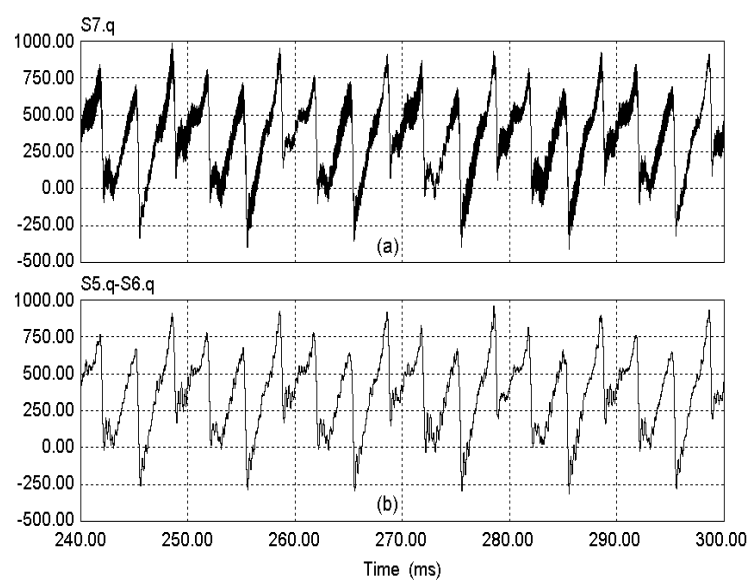

Figure 10. Imaginary power (a) $\mathrm{q}_{\text {inv }}$ (b) $\mathrm{q}_{\mathrm{g}}-\mathrm{q}_{\mathrm{L}}$

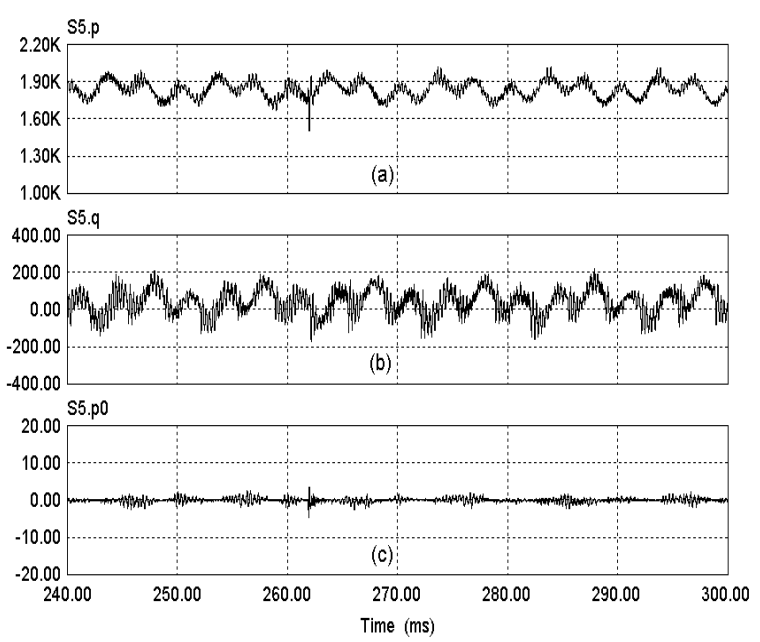

Figure 11.Power from grid (a) real power (b) imaginary power (c) zero sequence power

The power characteristics of the inverter haveto be reflected in the power at the DCbus. The power at the DC bus can be given by:

$$
P d c-b u s=v C 1 i C 1+v C 2 i C 2
$$

Where $i_{C 1}$ and $i_{C 2}$ are taken from Equations(14) and (15):

$$
\begin{aligned}
& v_{C 1} i_{C 1}= v_{C 1} \sum_{j=a, b, c} \frac{1}{v_{d c}}\left(v_{C 2} i_{i n v-j}+v_{p c c-j} i_{i n v-j}-\right. \\
&\left.L_{i n v} \frac{d i_{i n v-j}}{d t} i_{i n v-j}-R_{i n v} i_{i n v-j}^{2}\right) \\
& v_{C 2} i_{C 2}=v_{C 2} \sum_{j=a, b, c} \frac{1}{v_{d c}}\left(-v_{C 1} i_{i n v-j}+v_{p c c-j} i_{i n v-j}-\right. \\
&\left.L_{i n v} \frac{d i_{i n v-j}}{d t} i_{i n v-j}-R_{i n v} i_{i n v-j}^{2}\right)
\end{aligned}
$$

Substituting Equations (21) and(22) into (20) for $P_{d c}$ bus yields:

$$
\begin{aligned}
P_{d c-b u s}= & \frac{\left(v_{C 1}+v_{C 2}\right)}{v_{d c}} \\
& {\left.\left[\sum_{j=a, b, c} v_{p c c-j} i_{i n v-j}-L_{i n v} \frac{d i_{i n v-j}}{d t} i_{i n v-j}-R_{i n v} i_{i n v-j}^{2}\right)\right] }
\end{aligned}
$$

The DC capacitor currents may contain a zero sequence current; however, thepower at the DC-bus is free from zero sequence current. From (23), the power at the DC bus predominantly dependsupon the first part of the equation. Multiplying $v_{p c}$ and $i_{i v v}$ at the same phase results in instantaneous real power and instantaneous zero sequence power. The zero sequence power can exist in the DC busdepending upon both the zero sequence current from the load and the zero sequence voltage at the PCC.

The DC bus does not contain imaginary power. This fact agrees with the concept of instantaneousreactive power compensation using switchingdevices without energy storage [7]. The CC-VSI generates $q_{i v v}$ but it does not flow out of or into the DC-buscapacitors. According to Watanabe [9] and Peng [10], the imaginary power circulates among the phases In other words, instantaneously, the imaginary power required by one phase can be supplied by the other phase.

The DC-bus capacitors absorbthe small adive power to compensate for the losses in order to keep the DC voltage constant.

\section{CONCLUSION}

This paper explained the operation and the mathematical model of the CC-VSI as athree-phase shunt active power filter. The power inverter is operated to directly control the grid currentsto be sinusoidal and in phase with the gridvoltage. For the 
model, on the AC side, the CC-VSI can be represented as a voltage-controlled voltage source; while on the DC side, a current-controlledcurrent source represents the inverter.

From power flow analysis, the power distribution in the grid, loads and the inverter is identical to the system with conventional APF. It isobvious that the shunt APF is able to enhance the power capacity of the grid by compensating for thenon-active power. The inverter controls the imaginary power andthe zero sequence power. However, the non-active power does not emerge in the DC bus. The DC busonly contains real power as well as zero sequencepower. Computer simulation and experimental resultsclarify the theoretical observations.

\section{REFERENCES}

[1] M. El-Habrouk, M.K. Darwish and P.Mehta, “Active Power Filter: A Review". IEE Proc. Electr.Power.Appl, September 2000, pp. 403413.

[2] B. Singh, K. Al-Haddad and A. Chandra, $A$ "Review of Active Filter for Power Quality Improvements”. IEEE Trans. on Industrial Electronics, February 1999, pp. 960-971.

[3] Tumbelaka, H.H., L.J. Borle, and C.V.Nayar, "Application of A Shunt Active Power Filter to Compensate Multiple Non-linear Loads”. in Australasian Universities Power Engineering Conference (AUPEC). Melbourne, Australia: ACPE, 2002.

[4] Tumbelaka, H.H., L.J. Borle, and C.V.Nayar, "Analysis of a Series Inductance Implementation on a Three-phase Shunt Active Power Filter for Various Types of Non-linear Loads". Australian Journal of Electrical and Electronics Engineering, Engineers Australia, 2005.2(3): pp. 223-232.

[5] Watanabe, E.H., R.M. Stephan, andM. Aredes, "New Concepts of Instantaneous Active and Reactive Powers in Electrical Systems with Generic Loads”.IEEE Transactions on Power Delivery, 1993. 8(2): p. 697-703.

[6] L. Borle, Zero average current error control methods for bidirectional AC-DC converters. PhD thesis, Curtin University of Technology and the Australian Digital Theses Program: http://adt.caul.edu.au/

[7] L. Borle and C. V. Nayar, "RamptimeGurrent Control”. IEEE Applied Power Electronics Conference (APEC’96), March, 1996, pp 828834.

[8] Akagi, H., Y. Kanazawa, and A. Nabae, "Instantaneous Reactive Power Compensators Comprising Switching Devices without Energy
Storage Components”.IEEE Transactionson Industry Applications, 1984. IA-20(3): p. 625630.

[9] Akagi, H., S. Ogasawara, and H. Kim, The Theory of Instantaneous Power in Three-phase Four-wire Systems: A Comprehensive Approach. in IEEE IAS Annual Meeting 1999. p. 431-439

[10]Peng, F.-Z., G.W. Ott, and D.J. Adams, "Harmonic and Reactive Power Compensation based on the GeneralizedInstantaneous Reactive Power Theory for Three-phase Four-wire Systems".IEEE Transactions on Power Electronics, 1998. 13(6): p. 1174-1181. 